PROCEEDINGS of the Eighth International Driving Symposium on Human Factors in Driver Assessment, Training and Vehicle Design

THE LONG-TERM EFFECTIVENESS OF ECO-DRIVING TRANING:

\title{
A PILOT STUDY
}

Yiping Wu, Xiaohua Zhao, Jian Rong

College of Metropolitan Transportation, Beijing University of Technology

Beijing, China

Email:wyp900103@126.com

\begin{abstract}
Summary: Eco-driving has been proven to have a great benefit in reducing vehicle fuel consumption in many developed countries. However, the potential of ecodriving on energy-saving in China is not very clear. Taking three taxi drivers from Beijing Beiqi Taxi Group Company as examples, the petrol consumption, travel distance and many other factors influencing vehicle fuel use before and after ecodriving training were collected through survey forms. The short-term and long-term effect of eco-driving was compared. The results showed that, taking one month as the statistical cycle, the benefit of eco-driving in saving fuel consumption averaged is $19.04 \%$; while it reduced to $14.41 \%$ after four months from taking eco-driving training. Thus, drivers would partially regressed back to less economically driving behaviors and thus resulting in lower fuel savings after sometime. This study laid a foundation to evaluate the benefit of eco-driving in saving energy use.
\end{abstract}

\section{INTRODUCTION}

Eco-driving, the concept of changing driving behavior and vehicle maintenance practices to achieve a more economical and environmental driving pattern, has been proven to have a great potential to improve fuel efficiency and reduce greenhouse (GHG) emissions of existing vehicles (Martin et al., 2012). It has been reported that eco-driving could average reduce fuel consumption between 5 to $10 \%$, and the reduction percent could even increase to 20 to $50 \%$ for excellent performers (Barth \& Boriboonsomsin, 2009). With an increasing awareness of the costeffective benefits from eco-driving, more and more developed countries had launched campaigns to educate and coach drivers to drive more economically and environmentally (Luther \& Baas, 2011).

As the engine technologies, driving habits and driving population in China might be not always the same with other countries (Bai, 2011; Wei \& Zhang, 2004), the effectiveness of eco-driving in energy saving and emissions reduction might be also various. Before the current study, we have found that the potential of eco-driving in saving fuel consumption was 9 to $31 \%$ (Wu et al., 2014). However, both the studies of Wahlberg (2007) and Zarkadoula et al. (2007) indicated that, the effect of eco-driving training might be reduced after a long time. As our previous pilot study just tracked the fuel consumption of taxies for one month, it is necessary to further explore the long-term effect of eco-driving. 
In this study, we recruited the same three taxi drivers and tracked the fuel consumption of their vehicles after four months from eco-driving training. Then, the average fuel consumption in the period before eco-driving training, after eco-driving training in a short time and after eco-driving training in a long time were compared and analyzed. The study results would lay a foundation to evaluate the benefits of eco-driving in fuel saving in China.

\section{METHODS}

\section{Participants}

Three male drivers from Beijing Beiqi Taxi Group Company were recruited in this study. All were licensed drivers with a Chinese Class B driver's license. Some detailed demographic information of the participants was collected and shown in table 1. Besides, the type of the three cars used in this study was same (Hyundai Elantra, 1.6 liter, 2 years old).

Table 1. Demographic information of participants

\begin{tabular}{cccc}
\hline Driver number & Age (years) & Driving experience (years) & Average driving time (hour per day) \\
\hline 1 & 33 & 6 & 15 \\
2 & 42 & 20 & 8 \\
3 & 33 & 14 & 10 \\
\hline
\end{tabular}

\section{Experimental design}

The whole experiment included three stages: before eco-driving training, right after taking the eco-driving course and four months later after eco-driving training. Through the rest of the paper, we defined the three experimental stages as Normal, Short-term and Long-term, respectively. For each experimental stage, data of one month was collected. More detailed time arrangement was as follows:

- $\quad$ Normal: July 3, 2013 to August 2, 2013.

- $\quad$ Eco-driving training: August 5 to 6, 2013.

- $\quad$ Short-term: August 23, 2013 to September 23, 2013.

- $\quad$ Long-term: December 5, 2013 to January 4, 2014.

The contents of the survey form mainly included the travel time, travel distance, the amount of fuel using, time for using air condition, time for warming up and etc. Each of the participants was asked to fill the survey form every day.

\section{Eco-driving Training}

The training program in this study was a static approach. This static way aimed at urging drivers to apply general eco-driving techniques after learning through brochures (Martin et al, 2012). According to the common rules of eco-driving in developed countries (Lin, 2011; Shaheen et al., 
2012), the contents of eco-driving training were summarized as follows:

- $\quad$ Use route guide (e.g., mobile phone and navigator) to plan a route before starting a trip and try to avoid the crowed roads.

- $\quad$ Limit the time for warming up the engine less than 30 seconds.

- $\quad$ Avoid rapid starts and accelerate to $20 \mathrm{~km} / \mathrm{h}$ using 5 seconds.

- $\quad$ Shift up timely and avoid engine revolution at a high level.

- Try to maintain a steady speed of $100 \mathrm{~km} / \mathrm{h}$ on freeways.

- Anticipate traffic flow and decelerate smoothly.

- $\quad$ Show down the engine when stopping time is more than one minute.

- $\quad$ Optimize use of air condition and rear-window defroster.

- $\quad$ Avoid unnecessary weight and remove roof racks.

- $\quad$ Check tire pressure regularly and keeping tires properly inflated.

- Use the engine oil recommended by the manufacturer.

\section{DATA COLLECTION AND PROCESSING}

To find the benefits of eco-driving in energy saving, the amount of fuel consumption per the same travel distance should be got. Firstly, the summation of fuel consumption, travel distance and other influencing factors was calculated in table 2. As the selected three drivers were worked as volunteers in this research, they were willing to fill the survey form as requested responsibly and no missing data was found after our checking.

Table 2. Sum of survey data before and after eco-driving training

\begin{tabular}{ccccc}
\hline Survey data & Driver number & Normal & Short-term & Long-term \\
\hline & 1 & 483.00 & 542.00 & 503.00 \\
Travel time (h) & 2 & 227.50 & 286.00 & 319.00 \\
& 3 & 326.00 & 336.00 & 320.00 \\
& 1 & 10170.00 & 10750.00 & 10670.00 \\
Travel distance (km) & 2 & 3736.00 & 5398.00 & 5025.00 \\
& 3 & 5175.00 & 5980.00 & 5900.00 \\
Time for using air & 1 & 325.00 & 101.00 & 0.00 \\
condition (h) & 2 & 174.00 & 57.00 & 0.00 \\
& 3 & 248.00 & 65.00 & 0.00 \\
& 1 & 0.00 & 0.00 & 2.37 \\
Time for warming up & 2 & 0.00 & 0.00 & 1.08 \\
the engine (h) & 3 & 0.00 & 0.00 & 2.15 \\
& 1 & 1072.00 & 737.00 & 827.00 \\
\hline
\end{tabular}




\begin{tabular}{llll}
\hline 2 & 367.40 & 444.90 & 374.95 \\
3 & 467.00 & 406.00 & 420.00 \\
\hline
\end{tabular}

It is clear indicated that, in table 2, the time for air condition using in the first experimental period was obviously higher than that in the remaining two stages. Meanwhile, the time for warming up the engine only existed in the third phase. It is obvious that the temperature in these three experimental periods were distinctly different. Thus, the reason for the remarkable difference of the time for using air condition and warming up the engine might be closely related to the temperature, rather than the impact of eco-driving training. Hence, to avoid enlarging the benefits of eco-driving in energy saving, the fuel consumption resulting from air condition using and warming up the engine should be eliminated.

According to Shao's study (2001), the fuel consumption of an air condition for a car was about 1.5L per 100 kilometers in average. To remove the fuel use caused by air condition, the percentage of air condition using time in all the travel time was calculated. Then, the travel distance when using air condition was got. Thus, the fuel use caused by air condition could be obtained through Equation (1).

$$
Q_{i j}=\frac{\left(t_{i j} / T_{i j}\right) \times L_{i j}}{100} \times q_{0}
$$

Where

$Q=$ the fuel consumption caused by air condition when traveling,

$t=$ the time when using air condition while driving,

$T=$ the total travel time,

$L=$ the total travel distance,

$q_{0}=$ the average fuel consumption for a car, which is defined as $1.5 \mathrm{~L} / 100 \mathrm{~km}$ in this study,

$i=$ the driver number: $1,2,3$, and

$j=$ the experimental period: Normal, Short-term and Long-term.

According to the study results of eco-driving in Japan (Lin, 2011), the fuel consumption of a car caused by idling was about $0.221 \mathrm{cc} /$ second. Hence, the fuel consumption resulting from warming up the engine could be calculated. Overall, the fuel consumption resulting from air condition use and warming up the engine were obtained and displayed in table 3.

Table 3. Fuel consumption resulting from of using air condition and warming up the engine

Normal (L) Short-term (L) Long-term (L)


PROCEEDINGS of the Eighth International Driving Symposium on Human Factors in Driver Assessment, Training and Vehicle Design

\begin{tabular}{ccccccc}
\hline $\begin{array}{c}\text { Diver } \\
\text { number }\end{array}$ & $\begin{array}{c}\text { Using air } \\
\text { condition }\end{array}$ & $\begin{array}{c}\text { Warming up } \\
\text { the engine }\end{array}$ & $\begin{array}{c}\text { Using air } \\
\text { condition }\end{array}$ & $\begin{array}{c}\text { Warming up } \\
\text { the engine }\end{array}$ & $\begin{array}{c}\text { Using air } \\
\text { condition }\end{array}$ & $\begin{array}{c}\text { Warming up } \\
\text { the engine }\end{array}$ \\
\hline 1 & 102.65 & 0 & 30.05 & 0 & 0 & 0 \\
2 & 42.86 & 0 & 16.14 & 0 & 0 & 0.86 \\
3 & 59.05 & 0 & 17.35 & 0 & 0 & 1.71 \\
\hline
\end{tabular}

Then, the fuel consumption except for the influence of using air condition and warming up the engine was got and showed in table 4.

Table 4. Fuel consumption except for the influence of using air condition and warming up the engine

\begin{tabular}{cccc}
\hline Diver number & Normal (L) & Short-term (L) & Long-term (L) \\
\hline 1 & 969.35 & 706.95 & 825.12 \\
2 & 324.54 & 428.76 & 374.09 \\
3 & 407.95 & 388.65 & 418.29 \\
\hline
\end{tabular}

\section{RESULTS}

Using the data of total travel distance and fuel consumption from table 2 and table 4 , the fuel consumption per $100 \mathrm{~km}$ in Normal, Short-term and Long-term was calculated, respectively. As demonstrated in Figure 1, the vehicle fuel consumption per $100 \mathrm{~km}$ reduced at different levels after eco-driving training.

Comparing the fuel consumption in Normal and in Short-term, it is clear that the fuel consumption reduction of driver 1 is the most obvious than the remaining two drivers, and the driver 3 takes the second place. Using the decreased amount divided by original value, the potential of eco-driving in reducing fuel consumption separately is $31.00 \%, 8.56 \%$ and $17.56 \%$, corresponding to different drivers. Namely, taking one month as the statistical cycle, the benefit of eco-driving in saving fuel consumption is from about $9 \%$ to $31 \%$.

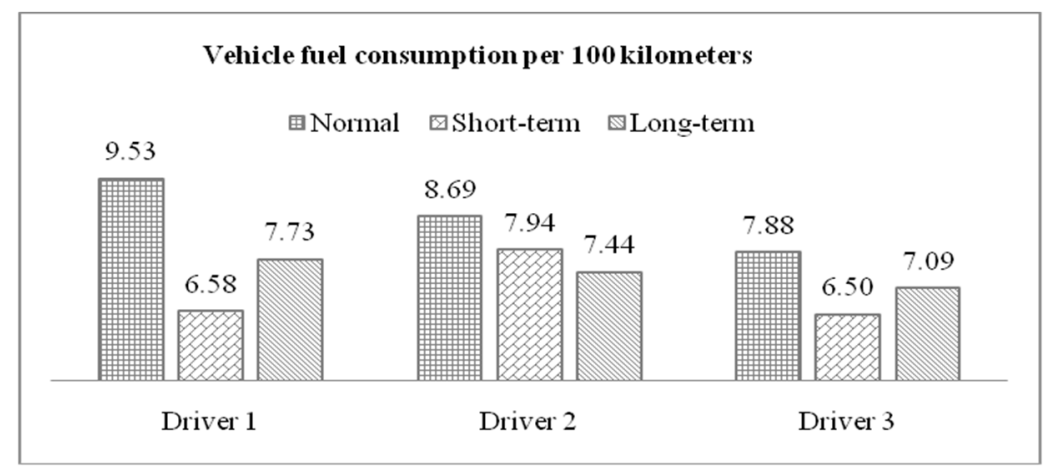

Figure 1. Vehicles' fuel consumption before and after Eco-driving training

Comparing the fuel consumption in Normal and in Long-term, the reduction of fuel consumption is also the largest for driver 1. But the reduction value is not as obvious as the difference between 
Normal and Short-term. Four months after eco-driving training, the function of eco-driving in reducing fuel consumption for the three drivers is $18.87 \%, 14.30 \%$ and $10.06 \%$, respectively. Namely, taking four months as the statistical cycle, the potential of eco-driving in saving fuel consumption is from about $10 \%$ to $18 \%$.

Based on the analysis results above, it indicated that the benefit of eco-driving in reducing fuel consumption averaged is $19.04 \%$ in a short-term, but decreased to $14.41 \%$ in a long-term. In average, the benefit of eco-driving training on fuel consumption reduction was smaller when the time was farther away from implementing eco-driving training. Thus, the current study results tested and verified that, comparing to the fuel consumption right after taking the eco-driving course, drivers partially regressed back to less environmentally friendly driving behaviors and thus resulting in lower fuel savings after a longer time.

\section{DISCUSSION}

This current study analyzed the potential of eco-driving in saving fuel consumption through tracking survey. To avoid enlarging the effectiveness of eco-driving training on vehicle fuel saving from the influence of temperature on warming up engine and air condition using, an average value finding from previous studies was used to eliminate the fuel consumption resulting from air condition and warming up the engine. Thus, the calculation results were not so accuracy, which needed to be further tested and verified in the future. Besides, the potential of eco-driving in saving fuel in our study might be reduced as the effectiveness of eco-driving training on optimally using air condition and warming up the engine was ignored.

In addition, it was worth noting that not every participant's driving behavior regressed back to less environmentally friendly after a longer time in this study, the fuel consumption of driver 2 was continuously declined for both short-term and long-term stages. So, in a future study, a large sample survey will be conducted to popularize the current results. Meanwhile, the future study also needs to involve different vehicle types (e.g., bus and truck).

Moreover, as it is easy to be affected by drivers' personal willingness, the results of drivers' subjective record might not reflect the real fuel consumption accurately. Therefore, we also planned to verify this study results through collecting and analyzing the vehicle running data by in-vehicle devices. Finally, this pilot study discussed the long-term effect of eco-driving from the tracked data after four months from receiving eco-driving training, the data of longer time after eco-driving training will be also continuously collected in the future.

\section{CONCLUSIONS}

Using the tracking survey data from three taxi drivers, this study analyzed the benefit of ecodriving in saving fuel consumption and compared the short-term and long-term effect of ecodriving. The study results indicated that, taking one month as the statistical cycle, the benefit of eco-driving in saving fuel consumption averaged is $19.04 \%$; while it reduced to $14.41 \%$ after 
four months from taking eco-driving training. Drivers would partially regressed back to less economically driving behaviors and thus resulting in lower fuel savings after a longer time. This study laid a foundation to evaluate the benefit of eco-driving in saving energy use, and it also provided suggestion for developing an executable eco-driving training program.

\section{REFERENCES}

Barth, M., \& Boriboonsomsin, K. (2009). Energy and Emissions Impacts of a Freeway-based Dynamic Eco-driving System. Transportation Research Part D, 8: 400-410.

Bai, Y. (2011). Research on Driving Energy-saving Technology. Master Thesis, Chang' an University, China.

Luther, R., \& Baas, P. (2011). Eco-driving Scoping Study. New Zealand: AA Research Foundation.

Lin, R. (2011). The International Situation for Promoting Eco-driving. Taiwan: Industrial Technology Research Institute.

Martin, E., Chan, N. D., \& Shaheen, S. A. (2012). Understanding How Ecodriving Public Education can Result in Reduced Fuel Use and Greenhouse Gas Emissions. In the 91st Annual Meeting of Transportation Research Board, Washington, D.C.

Shaheen, S., Martin, E., \& Finson, R. (2012). Ecodriving Carbon Footprinting: Understanding How Public Education Can Reduce Greenhouse Gas Emissions and Fuel Use. (CA-MTI-122808). San Jose: Mineta Transportation Institute.

Shao, L. (2001). Technology and Awareness of Automobile Energy Saving. ENERGY TECHNOLOGY, 1(22): 27-29.

Wei, H, \& Zhang, W. (2004). Study on Factors Determining Driving Safety in China and the US. China Safety Science Journal, 14(9): 24-28.

Wu, Y. P., \& Zhao, X. H. (2014). A Pilot Study to Explore the Potential of Eco-driving on Fuel Consumption Reduction. ROAD TRAFFIC \& SAFETY, 14(1): 53-55.

Wahlberg, A. E. (2007). Long-term Effects of Training in Economical Driving: Fuel Consumption, Accidents, Driver Acceleration Behavioral and Technical Feedback. International Journal of Industrial Ergonomics, 37: 333-343.

Zarkadoula, M., Zoidis, G., \& Tritopoulou, E. (2007). Training Urban Bus Drivers to Promote Smart Driving: A Note on a Greek Eco-driving Pilot Program. Transportation Research Part D, 12: 449-451. 